\title{
An improved method for RNA isolation from plants using commercial extraction kits
}

\author{
Elżbieta Kalinowska ${ }^{凶}$, Maria Chodorska, Elżbieta Paduch-Cichal and Karolina Mroczkowska \\ Warsaw University of Life Sciences-SGGW, Faculty of Horticulture and Landscape Architecture, Department of Plant Pathology, Warsaw, Poland
}

\begin{abstract}
Isolation of RNA from plants rich in secondary metabolites using commercial kits often results in contaminated preparations which are not suitable for downstream applications. Although many specific protocols appropriate for plants with a high content of phenolics, anthocyanins and polysaccharides have been developed, these are often expensive, time consuming and not applicable to different types of tissues. This study presents a simple and efficient modification of RNA extraction from different types of tissues using two commercial reagent kits. By simple improvement, we routinely obtained high-quality RNA of the following plants: the blackcurrant bush, black chokeberry bush, pear tree, apricot tree, apple tree, hardy kiwi, tangerine tree, highbush blueberry and cranberry plant.
\end{abstract}

Keywords: total RNA, secondary metabolites

Received: 15 March, 2012; revised: 28 May, 2012; accepted: 16 July, 2012; available on-line: 24 July, 2012

\section{INTRODUCTION}

The extraction of high-quality RNA from tissues with a high level of secondary metabolites using commercial kits is often difficult. One of the biggest issues during RNA extraction concerns phenolic compounds, which oxidize and form quinones. Aromatic compounds bind RNA, which hinders downstream applications (Loomis, 1974). Although many specific protocols appropriate for plants rich in secondary metabolites have been developed, they are often expensive, time consuming and not applicable to woody tissues (Chomczynski \& Sacchi, 1987; Ding et al., 2007; Camacho-Villasana et al., 2002; Liao et al., 2004; Tong et al., 2012).

Initially we tried to obtain RNA from highbush blueberry (Vaccinium corymbosum L.) tissues using two commercial kits: the Spectrum RNA Kit (Sigma Aldrich, St. Louis, MO, USA) and the RNeasy ${ }^{\circledR}$ (Qiagen Inc., Valencia, CA, USA) procedure as modified by MacKenzie et al. (1997) (available on the Qiagen website), but in both cases the quantity or/and quality of RNA obtained was unsuitable for RT-PCR. After the failed RNA isolation with commercial kits, we tried LiCl- (Verwoerd et al., 1989) and phenol-based protocols (Ghawana et al., 2011). Unfortunately, the RNA pellets were yellowish in both, suggesting contamination with non-nucleic acid compounds. Therefore, we reasoned that a modified homogenization method of samples could improve the quality and yield of commercial RNA extraction kits. In this study, we modified the RNA extraction procedures of two commercial reagents: the Spectrum ${ }^{\mathrm{TM}}$ Plant Total RNA Kit and an alternative procedure of RNA isolation from plant tissues rich in secondary metabolites using the RNeasy ${ }^{\circledR}$ Plant Mini Kit developed by MacKenzie et al. (1997).

\section{MATERIAL AND METHODS}

Plant material. The highbush blueberry was grown under normal environmental conditions on the Blueberry Experimental Farm in Błonie near Prażmów belonging to the Department of Pomology of the Warsaw University of Life Sciences (SGGW). The blackcurrant bush (Ribes nigrum L.), black chokeberry bush (Photinia melanocarpa Michx.), pear tree (Pyrus communis L.), apricot tree (Prunus armeniaca L.), apple tree (Malus sp. Mill.), hardy kiwi (Actinidia arguta Siebold \& Zucc.) and cranberry plant (Vaccinium macrocarpon L.) were collected from an experimental field located at the university campus. The tangerine tree (Citrus reticulata Blanco) was acquired at a local flower shop. Mature leaves, fruits and barks were collected and stored at $-80^{\circ} \mathrm{C}$ until further use.

RNA extraction. All the glassware, mortars and pestles were treated with RNaseZAPTM (Sigma Aldrich) and autoclaved. Plasticware (tips and tubes) were certified as RNase- and DNase-free. To limit the exposure to noxious components of extraction buffers (e.g., $\beta$-mercaptoethanol (B-ME), sodium lauroyl sarcosinate, guanidine thiocyanate) the homogenization was conducted in a fume hood.

Modification of the Spectrum ${ }^{\text {TM }}$ Plant Total RNA Kit protocol. Samples (up to $50 \mathrm{mg}$ ) were ground under liquid nitrogen to fine powder using a mortar and a pestle. Subsequently, $500 \mu \mathrm{l}$ of Lysis Solution was added, and all was ground to obtain a homogenous mixture. Trituration was carried on until the sample was completely thawed. Then, $300 \mu \mathrm{l}$ of Lysis Solution were added and mixed in by grinding. The mixture $(\sim 800 \mu \mathrm{l})$ was transferred to a 2 -ml collection tube and incubated without shaking at room temperature for 10 minutes. The following steps of RNA extraction were conducted using the Spectrum ${ }^{\mathrm{TM}}$ Plant Total RNA Kit protocol A.

Modification of the alternative procedure of the RNeasy ${ }^{\circledR}$ Plant Mini Kit protocol (MacKenzie et al., 1997). Samples (up to $50 \mathrm{mg}$ ) were ground under liquid nitrogen to fine powder using a mortar and pestle. Then, $500 \mu$ l of extraction buffer (4 M guanidine thiocyanate, $0.2 \mathrm{M}$ sodium acetate, $\mathrm{pH}$ 5.0, $25 \mathrm{mM}$ EDTA, 2.5\% $(\mathrm{w} / \mathrm{v})$, polyvinylpyrrolidone (PVP) and 1\% (v/v) B-ME) was added, and the grinding was continued to obtain a

凶e-mail: elzbieta kalinowska@sggw.pl

Abbreviations: B-ME, $\beta$-mercaptoethanol; EDTA, ethylenediaminetetraacetic acid; PVP, polyvinylpyrrolidone; PVPP, polyvinylpolypyrrolidone; RT-PCR, reverse transcription-polymerase chain reaction 
Table 1. Yield and purity of RNA isolated from blueberry plant parts using different methods

\begin{tabular}{|c|c|c|c|}
\hline Extraction method & Tissue & $A_{260 / 280}$ & $\begin{array}{l}\text { Yield } \\
(\mu \mathrm{g} / 50 \mathrm{mg} \text { FW) }\end{array}$ \\
\hline \multirow{3}{*}{ Present study (modification of Spectrum ${ }^{\mathrm{TM}}$ Plant Total RNA Kit protocol) } & Bark & $2.09 \pm 0.02$ & $21.61 \pm 0.34$ \\
\hline & Mature leaf & $2.09 \pm 0.02$ & $20.62 \pm 0.15$ \\
\hline & Flower & $2.06 \pm 0.03$ & $69.74 \pm 2.19$ \\
\hline \multirow{3}{*}{ Spectrum $^{\text {TM }}$ Plant Total RNA Kit basic protocol } & Bark & $2.16 \pm 0.06$ & $0.27 \pm 0.04$ \\
\hline & Mature leaf & $2.16 \pm 0.02$ & $1.13 \pm 0.07$ \\
\hline & Flower & $2.14 \pm 0.04$ & $1.75 \pm 0.05$ \\
\hline \multirow{3}{*}{ RNeasy ${ }^{\circledR}$ alternative procedure (MacKenzie et al., 1997) } & Bark & $2.16 \pm 0.08$ & $2.76 \pm 0.05$ \\
\hline & Mature leaf & $1.59 \pm 0.02$ & $0.47 \pm 0.02$ \\
\hline & Flower & $2.08 \pm 0.05$ & $0.45 \pm 0.03$ \\
\hline
\end{tabular}

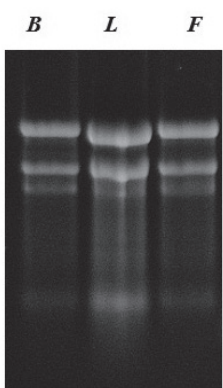

1

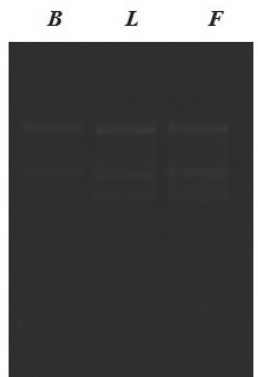

2

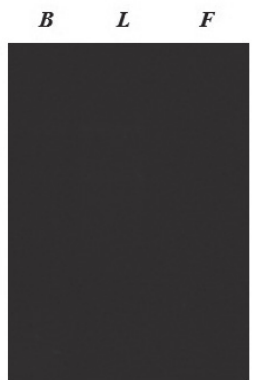

3
Figure 1. Denaturing gel electrophoresis of RNA extracted from highbush blueberry using different protocols.

(1) present study - modification of Spectrum ${ }^{\mathrm{TM}}$ Plant Total RNA Kit protocol; (2) original Spectrum ${ }^{\text {TM }}$ Plant Total RNA Kit protocol; (3) RNeasy ${ }^{\circledR}$ procedure modified by MacKenzie et al. (1997). RNA was purified from: bark (B), leaf $(\mathrm{L})$ and flower $(\mathrm{F})$.
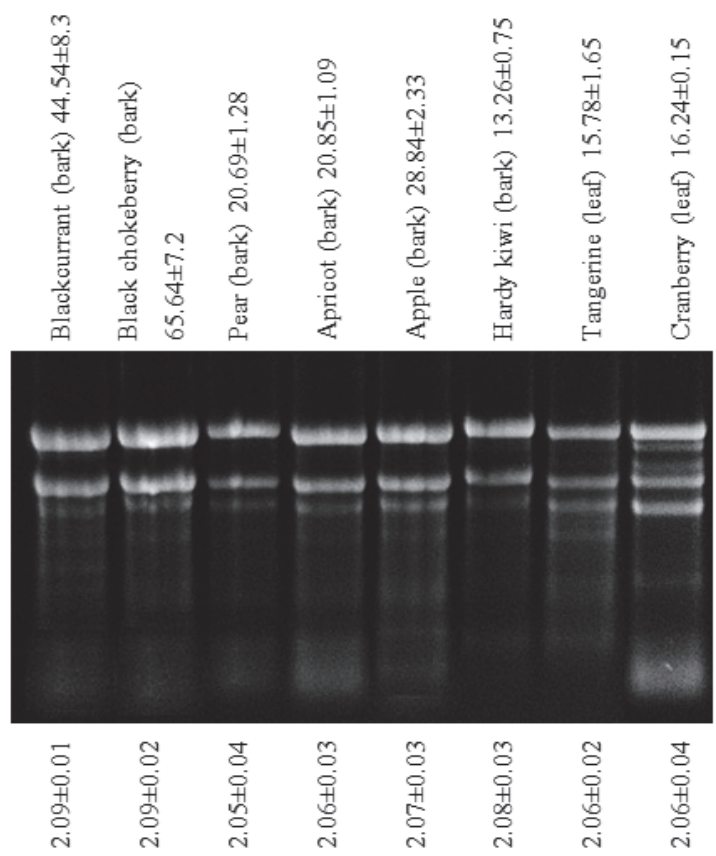

Figure 2. Denaturing gel electrophoresis of RNA isolated from different plants using modification of the alternative procedure of the RNeasy ${ }^{\circledR}$ Plant Mini Kit protocol (MacKenzie et al., 1997)). The A260/280 ratios, plant and tissue types along with RNA yield $(\mu \mathrm{g} / 50 \mathrm{mg}$ ) are given below and above each panel, respectively. homogenous mixture and carried on until the sample was completely thawed. Next, $300 \mu \mathrm{l}$ of extraction buffer and $60 \mu \mathrm{l}$ of $20 \%$ sodium lauroyl sarcosinate were added and mixed in by further grinding. The mixture $(\sim 860 \mu \mathrm{l})$ was transferred to a 2 -ml collection tube and incubated with vigorous shaking at room temperature for 10 minutes. The following steps of RNA isolation were performed in accordance with the instructions of the MacKenzie's alternative procedure (MacKenzie et al., 1997).

RNA quantity, quality and RT-PCR. RNA was analyzed primarily by running $1 \mu$ l of each sample on $1.2 \%$ denaturing-formaldehyde agarose gel stained with ethidium bromide. The concentration and purity of the extracted RNA were analyzed by means of a Tecan Infinite ${ }^{\circledR} 200$ PRO NanoQuant spectrophotometer (Tecan Group Ltd., Switzerland).

Total RNA from blueberry leaves, flowers and bark were used for one-step RT-PCR. Amplification was performed using the Titan One Tube RT-PCR System (Roche, Germany) and the primers specific to the ribulose 1,5-bisphosphate carboxylase chloroplast $(\mathrm{R} b c 1)$ gene (Sanchez-Navarro et al., 2005).

\section{RESULTS AND DISCUSSION}

Most of the published RNA isolation protocols employing denaturing organic solvents (phenol or chloroform), denaturing agents (guanidine thiocyanate), reducing agents (B-ME) and polymers that bind contaminants (PVP, polyvinylpolypyrrolidone (PVPP)) can successfully be used to obtain RNA from plant material with a high level of secondary metabolites. Unfortunately, LiCl- and phenol-based protocols as well as kits with reagents dedicated to plants rich in secondary metabolites did not result in obtaining high-quality RNA from blueberry tissues. Therefore, we presumed that during the first step of RNA isolation tissues with a high content of secondary metabolites could have had insufficient contact with extraction buffers.

Homogenization with extraction buffer improved the quality and quantity of RNA when using both the Spectrum $^{\mathrm{TM}}$ Plant Total RNA Kit and the alternative procedure of the RNeasy ${ }^{\mathbb{P}}$ Plant RNA Mini Kit developed by MacKenzie et al. (1997). The quantity and purity of blueberry RNA preparations were found to be superior when using this simple modification as compared to the original kit protocols (Table 1). RNA concentration was at least ten times improved. Electrophoresis on agarose formaldehyde gel resolved $26 \mathrm{~S}$ and $18 \mathrm{~S}$ rRNA bands 


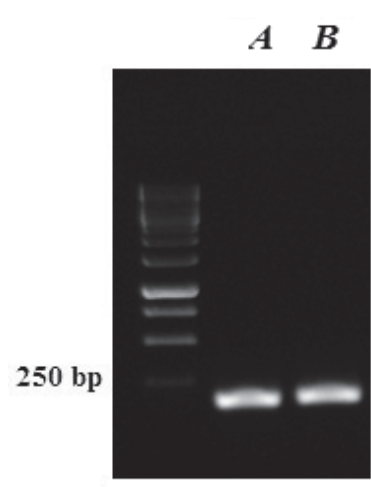

1

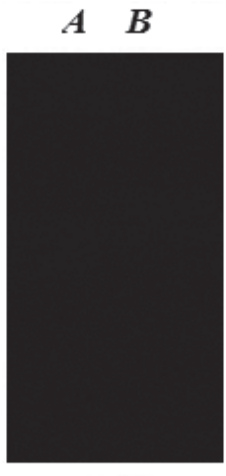

2
Figure 3. Agarose gel analysis of RT-PCR assays with the Rbc1specific primers on total RNA extracts from highbush blueberry bark tissue.

(1A) RNA obtained with a modified Spectrum ${ }^{\text {TM }}$ Plant Total RNA Kit protocol; (1B) RNA obtained with a modified alternative procedure of the RNeasy ${ }^{\circledR}$ Plant Mini Kit protocol (MacKenzie et al., 1997); (2A) RNA obtained with the Spectrum ${ }^{\text {TM }}$ Plant Total RNA Kit protocol; (2B) RNA obtained with an alternative procedure of the RNeasy ${ }^{\circledR}$ Plant Mini Kit protocol (MacKenzie et al., 1997).

with no DNA contamination in all samples (Fig. 1 and Fig. 2). Additionally, RNA preparations from nine different woody plants did not reveal the high level of RNA degradation that may occur during isolation. The A260/280 ratios of RNA extracts indicated there was no protein, phenol or other contaminants that absorb strongly at or near $280 \mathrm{~nm}$. RNA extracts obtained with our modification were suitable for RT-PCR. Amplified fragments of the blueberry $\mathrm{R} b c 1$ gene (186 bp) were visible on agarose gel, whereas the quality and quantity of RNA extracts obtained in accordance with the manufacturer's instructions were not applicable to amplification (Fig. 3). The results of this study indicate that, apart from the choice of chemical reagents, the method of tissue homogenization is a critical step during RNA extraction from "difficult" sources.

\section{Acknowledgements}

This work was supported by grant N N310 036038 from the Ministry of Science and Higher Education.

\section{REFERENCES}

Camacho-Villasana YM, Ochoa-Alejo N, Walling L, Bray EA (2002) An improved method for isolating RNA from dehydrated and nondehydrated Chili pepper (Capsicum annum L.) plant tissues. Plant Mol Biol Rep 20: 407-414.

Chomczynski P, Sacchi N (1987) Single-step method of RNA isolation by acid guanidinium thiocyanate-phenol chloroform extraction. Anal Biochem 162: 156-159.

Ding LW, Sun QY, Wang ZY, Sun YB, Xu ZF (2008) Using silica particles to isolate total RNA from plant tissues recalcitrant to extraction in guanidine thiocyanate. Anal Biochem 374: 426-428.

Ghawana S, Paul A, Kumar H, Kumar A, Singh H, Bhardwaj PK (2011) An RNA isolation system for plant tissues rich in secondary metabolites. BMC Res Notes 4: 85.

Liao Z, Chen M, Guo L, Gong Y, Tang F, Sun X, Tang K (2004) Rapid isolation of high-quality total RNA from Taxus and Ginkgo. Prep Biochem Biotechnol 34: 209-214.

Loomis MD (1974) Overcoming problems of phenolics and quinones in the isolation of plant enzymes and organelles. Methods Ensymol 31: $528-544$.

MacKenzie DJ, McLean MA, Mukerji S, Green M (1997) Improved RNA extraction from woody plants for the detection of viral pathogens by reverse transcription-polymerase chain reaction. Plant Dis 81: $222-226$.

Sanchez-Navarro JA, Aparicio F, Herranz MC, Minafra A, Myrta A, Pallas V (2005) Simultaneous detection and identification of eight stone fruit viruses by one-step RT-PCR. Eur J Plant Pathol 111: 7784.

Tong Z, Qu S, Zhang J, Wang F, Tao J, Gao Z, Zhang Z (2012) A Modified Protocol for RNA extraction from different peach tissues suitable for gene isolation and Real-Time PCR analysis. Mol Biotechnol 50: 229-236.

Verwoerd TC, Dekker BM, Hoekema A (1989) A small-scale procedure for the rapid isolation of plant RNAs. Nucleic Acids Res 17: 2362 . 
